\title{
G31P, CXCR1/2 inhibitor, with cisplatin inhibits the growth of mice hepatocellular carcinoma and mitigates high-dose cisplatin-induced nephrotoxicity
}

\author{
LINGYUN LI $^{1,2^{*}}$, MUHAMMAD NOMAN KHAN ${ }^{1 *}$, QIANG LI ${ }^{3}$, XIANGYU CHEN ${ }^{2}$, JING WEI $^{1}$, \\ BING WANG ${ }^{1}$, JYA-WEI CHENG ${ }^{4}$, JOHN R. GORDON ${ }^{5}$ and FANG LI ${ }^{1}$
}

\begin{abstract}
${ }^{1}$ Department of Immunology, Dalian Medical University, Dalian, Liaoning 116044; ${ }^{2}$ Department of Immunology,
Tongji Medical College, Huazhong University of Science and Technology, Wuhan, Hubei 430030;

${ }^{3}$ Jilin Medical College, Jilin 132013, P.R. China; ${ }^{4}$ Institute of Biotechnology, Department of Life Science, National Tsing Hua University, Hsinchu 300, Taiwan, R.O.C.; ${ }^{5}$ The Division of Respirology, Critical Care and Sleep Medicine, Royal University Hospital, University of Saskatchewan, Saskatoon, SK S7N 0W8, Canada
\end{abstract}

Received August 18,2014; Accepted September 25, 2014

DOI: $10.3892 /$ or.2014.3659

\begin{abstract}
Cisplatin (DDP), a cytotoxic antitumor drug, functions in a dose-dependent manner. However, the pursuit for high-dose therapeutic effects leads to more serious side effects including kidney toxicity. Nephrotoxicity caused due to endothelial cell dysfunction and neutrophils infiltration in kidneys. Interleukin-8 (IL-8) is an ELR+ chemokine binds with CXCR $1 / 2$ receptors and its role is primarily in neutrophils recruitment and also involved in invasion, angiogenesis and metastasis of different solid tumors including liver cancer. G31P, a CXCR1/2 antagonist, binds with CXCR1/2 with high affinity, and acts as an anti-inflammatory and antitumor agent. In the present study, we examined the antitumor effects of G31P and DDP on mouse liver cancer cells, and the effects exerted by G31P on cisplatin-induced renal injury. In vitro, effects of the G31P and DDP regimen on $\mathrm{H} 22$ cell proliferation were investigated by MTT assay. In vivo BALB/c mice were inoculated subcutaneously with $1 \times 10^{6} \mathrm{H} 22$ cells and treated after one week with a high single dose of DDP with and without G31P on alternative days until the experiment was terminated. On the 15 th day the mice were sacrificed, dissected and kidney tissues were analyzed using H\&E staining. Myeloperoxidase (MPO) activity was assessed and RT-PCR was performed to detect inflammatory cytokines. Solid tumors were weighed for tumor growth and performed pathological examination,
\end{abstract}

Correspondence to: Dr Fang Li, Department of Immunology, Dalian Medical University, 9 Lushunnan Road, Dalian, Liaoning 116044, P.R. China

E-mail: lifang16@hotmail.com

*Contributed equally

Key words: G31P, CXCR1/2, cisplatin, nephrotoxicity, mice hepatocarcinoma immunohistochemistry and western blotting were performed to detect tissue-related protein expressions in tumor tissue. The tumor inhibitory rate of DDP, G31P and DDP+G31P groups was $38.40,40.74$ and $74.80 \%$, respectively, and the general state of mice in the DDP+G31P group was significantly improved as compared to the DDP group. The results indicated that G31P with DDP significantly inhibited the proliferation while the growth of $\mathrm{H} 22$ cell carnimona in vitro and in vivo enhanced the efficacy of cisplatin in cancer treatment with reduced side effects on acute renal failure.

\section{Introduction}

Hepatocellular carcinoma (HCC) is the sixth most common cancer and the third most common cause of mortality from cancer worldwide (1). Cisplatin (DDP) has broad-spectrum antitumor effects used in the chemotherapy of different malignancies including HCC. However, serious side-effects were observed with high doses and multiple courses of treatment $(2,3)$. Nephrotoxicity is frequent and remains the major limitation in cisplatin-based chemotherapy (4). Previous findings suggested that cisplatin injury causes endothelial cell dysfunction and infiltration of circulating leukocytes, particularly neutrophils $(4,5)$, leading to the excretion of locally secreted cytokines/chemokines such as tumor necrosis factor (TNF), which contributes to the initiation and progression of renal disease (6). However, clinically alternative strategies such as immunotherapy and their combinations with chemotherapy have been suggested to reduce the side effects. Inhibition of proinflammatory mediators in DDP-induced ARF is associated with reduction in renal neutrophils (7).

The expression of interleukin (IL)-8, an ELR-CXC chemokine, is involved as a chemotactic attractant of neutrophils, $\mathrm{T}$ cells and other inflammatory cells by binding to its receptors CXCR1 and CXCR2 (8), found at the inflammation site of various types of human cancer, including HCC, and is regulated by many tumor microenvironmental factors, such as hypoxia and tumor necrosis factor (9). 
CXCL8 $8_{(3-72)} \mathrm{K} 11 \mathrm{R} / \mathrm{G} 31 \mathrm{P}(\mathrm{G} 31 \mathrm{P})$ is a recombinant compound produced from human IL-8 using gene site-directed mutagenesis by introducing a Lys 11 to Arg substitution and a Gly 31 to Pro substitution to generate a broad spectrum ELR-CXC chemokine antagonist, human CXCL8 $8_{(3-72)} \mathrm{K} 11 \mathrm{R} / \mathrm{G} 31 \mathrm{P}(10,11)$. G31P has been shown to bind to CXCR1/2, block signal transduction and is considered as anti-inflammatory preparation with 'broad spectrum' anti-inflammatory activity (12-14). G31P exerts inhibitory effects on the growth, metastasis and angiogenesis of malignant tumors such as prostate cancer and NSCLC (15). G31P was also previously found to play an anti-atherosclerosis role (16).

In the present study, the antitumor effects of DDP and G31P on mouse HCC in vitro and in vivo were investigated, as well as the effect of high-dose DDP-induced acute renal failure. The combine use of DDP and G31P resulted in the inhibition of neutrophil infiltration, cytokine release and amelioration of ARF.

\section{Materials and methods}

Cell lines, animals and reagents. Female Balb/c mice (18-22 g) were provided by the SPF Animal Center, Dalian Medical University (Dalian, China). H22 mouse HCC cells were cultured in ascites fluid, and after 7 days, second generation mice were used in experiments. DDP was purchased from Haosheng Pharmaceutical Corporation (Lianyungang, China). G31P was produced by the Institute of Biotechnology, National Tsing Hua University (Hsinchu, Taiwan).

MTT assay. The second generation $\mathrm{H} 22$ mouse HCC cells were collected and maintained in a complete RPMI-1640 medium containing $10 \%$ fetal bovine serum (HyClone, Australia). The cells were plated in $96-$ well plates $\left(2 \times 10^{4} / \mathrm{ml}\right.$ cells/well in $100 \mu 1$ of medium) and maintained in a humidified incubator with $5 \% \mathrm{CO}_{2}$ at $37^{\circ} \mathrm{C}$. After $12 \mathrm{~h}$ of incubation, the cells were treated with or without DDP (at a doses of $0.25,5$ and $10 \mu \mathrm{g} / \mathrm{ml})$ with or without G31P $(0.1 \mu \mathrm{g} / \mathrm{ml})$. After $24 \mathrm{~h}, 10 \mu \mathrm{l}$ of MTT $(5 \mathrm{mg} / \mathrm{ml})$ was added to each well and incubated for $4 \mathrm{~h}$. The reaction was stopped by adding $100 \mu \mathrm{l}$ of dimethyl sulfoxide. Absorbance was measured at $570 \mathrm{~nm}$ and the cell proliferation inhibition rate was calculated.

DDP tolerance test in mice. To determine the maximum survival dose of DDP, Balb/c mice were randomly divided into 5 groups on the basis of DDP dosage. Each group $(n=6)$ was treated with different concentrations of single-dose DDP starting from 11, $12.5,14$ and $15.5 \mathrm{mg} / \mathrm{kg}$ intraperitoneally (i.p.), and the control group was injected with same volume of saline.

Establishment of animal model. $\mathrm{H} 22$ mouse $\mathrm{HCC}$ cells $\left(1 \times 10^{6}\right)$ in $0.2 \mathrm{ml}$ suspension were injected subcutaneously into the posterior right flank of mice for tumor implantation. After 7 days, the mice were randomly divided into four groups: DDP ( $n=12)$, DDP+G31P ( $=12)$, G31P $(n=20)$ and the control group $(n=20)$. The DDP and DDP+G31P groups were treated with a single dose of DDP $(12.5 \mathrm{mg} / \mathrm{kg}$ i.p.). Mice of the $\mathrm{DDP}+\mathrm{G} 31 \mathrm{P}$ and G31P groups were treated with G31P $(500 \mu \mathrm{g} /$ $\mathrm{kg}$; subcutaneously) on alternative days, while other groups were treated with isovolumic saline. Following treatment, the mice were observed weight and survival rate was recorded. On the 9th day of drug treatment, the mice in each group were sacrificed. Blood from eye canthus vein from each mouse was aspirated to measure the serum urea nitrogen (BUN) and creatinine (SCr) levels and tumor samples from each mouse were weighed and preserved for subsequent analysis. The tumor volume was calculated using the formula: Tumor volume $=\left(\right.$ length $\mathrm{x}$ width $\left.{ }^{2}\right) / 2$.

Hematoxylin and eosin analysis. Kidney and tumor tissue samples from the DDP, DDP+G31P, G31P and control groups were fixed in $4 \%$ paraformaldehyde and embedded in paraffin using standard procedures. Sections $(6 \mu \mathrm{m})$ were cut and stained with hematoxylin and eosin (H\&E). For the kidney samples, tubular damage was estimated by examining 8-10 high-power fields (HPF; magnification x200) per section by using a scoring system based on the percentage of damaged tubules per field: $1,<25 \% ; 2,25-50 \% ; 3,50-75 \%$; and $4,>75 \%$. The mean score of each animal was compared.

Immunohistochemistry. Tumor samples were embedded in O.C.T. Compound and cut into slices $(8-\mu \mathrm{m})$ in cryostat $\left(-22^{\circ} \mathrm{C}\right)$. The sections were warmed at room temperature for $30 \mathrm{~min}$, fixed in ice-cold acetone for $10 \mathrm{~min}$, and rinsed three times with phosphate-buffered saline (PBS). The endogenous peroxidase activities were blocked by $3 \% \mathrm{H}_{2} \mathrm{O}_{2}$ for $10 \mathrm{~min}$. Sections were then rinsed three times with PBS, incubated with a protein blocker solution of $10 \%$ normal goat serum for $15 \mathrm{~min}$ at room temperature, and washed three times with PBS. Sections were subsequently incubated overnight at $4^{\circ} \mathrm{C}$ with primary antibodies: rabbit anti-VEGF-A antibody (1:200), rabbit anti-NF- $\mathrm{B}$ p65 antibody (1:200) and rabbit anti-EGFR antibody (1:200) (all from Santa Cruz Biotechnology, Inc., Santa Cruz, CA, USA). The following day, the slides were rinsed three times with PBS and incubated in streptavidin peroxidase-conjugated and biotinylated goat antirabbit IgG (1:5,000; Zhongshan Biotech, Beijing, China) for $1 \mathrm{~h}$ at $37^{\circ} \mathrm{C}$. Subsequently, the slides were washed three times with PBS and stained with 3,3'-diaminobenzidine (DAB) (Zhongshan Biotech) for 6 min and clear DAB in running tape water for $5 \mathrm{~min}$. The sections were stained with hematoxylin staining solution for $30 \mathrm{sec}$ and rinsed under running water. Dehydration was performed following standard procedure in diluted alcohol solutions and the sections were sealed with neutral resins.

Western blot analysis. After protein extraction from tumor and kidney tissue samples from DDP, DDP+G31P, G31P and control groups, each protein sample was separated by $10 \%$ SDS-PAGE gel. After electrophoresis, the proteins were transferred to PVDF membranes (Amersham, Buckinghamshire, UK). The membranes were incubated with blocking solution containing $0.3 \%$ Tween-20, and 10\% skim-dried milk in TBS for $2 \mathrm{~h}$. The primary antibodies of EGFR (rabbit antibody, 1:200), MMP-2 (goat antibody, 1:200), VEGF-A (rabbit antibody 1:200) (all from Santa Cruz Biotechnology) were incubated with proteins PVDF of tumor overnight at $4^{\circ} \mathrm{C}$. The following day, the primary antibody was removed by washing in TBST three times. The membranes were incubated with horseradish peroxidase-conjugated goat anti-rabbit (or rabbit anti-goat) 
secondary antibody (1:5,000; Zhongshan Biotech) for $1 \mathrm{~h}$ at room temperature. Following three washes in TBST, bands were visualized by electrochemical luminescence (ECL). The amount of each protein was determined from the intensity of the band. To verify equal protein loading, the $\beta$-actin level in each lane was examined with anti- $\beta$-actin antibody. Bands were semi-quantified with the software Image $\mathrm{J} 2 \mathrm{x}$.

Evaluation of BUN and SCr. Blood urea nitrogen (BUN) and $\mathrm{SCr}$ levels were measured using an automatic biochemical analyzer according to the manufacturer's instructions.

Determination of MPO activity of kidney. The activity of myeloperoxidase (MPO), an enzyme present in neutrophils, was used as a marker for neutrophil infiltration. Kidney tissues were homogenized in $10 \%(\mathrm{w} / \mathrm{v})$ of $20 \mathrm{mM}$ phosphate buffer (pH 7.4). After centrifugation at $15,000 \mathrm{rpm}$ for $20 \mathrm{~min}$, the pellet was sonicated and resuspended in 2,350 $\mathrm{mM}$ potassium phosphate buffer ( $\mathrm{pH}$ 6.0) containing $0.5 \%$ hexadecyltrimethylammonium bromide. After being heated at $60^{\circ} \mathrm{C}$ for $2 \mathrm{~h}$, the samples were centrifuged at $10,000 \mathrm{rpm}$ for $10 \mathrm{~min}$. The supernatant was added to $2,250 \mathrm{mM}$ phosphate buffer ( $\mathrm{pH}$ 6.0) containing $0.167 \mathrm{mg} / \mathrm{ml}$ o-dianisidine and $5 \times 10^{-4} \%$ hydrogen peroxidase. MPO activity was measured using s spectrophotometer. The change in absorbance was measured at $460 \mathrm{~nm}$ at $37^{\circ} \mathrm{C}$, using a SpectraMax microplate reader (Molecular Devices, Sunnyvale, CA, USA). Results were expressed as a unit of MPO activity/g of wet tissue.

RT-PCR detection of inflammatory cytokines in kidney. TRIzol reagent (Takara, Dalian, China) was used to extract total RNA from the kidney samples of DDP, DDP+G31P, G31P and the control group according to the manufacturer's instructions. Synthesis of complementary DNA (cDNA) was performed with reverse transcriptase and oligo(dT) primer (Takara) as per instructions on the product data sheet. PCR primers used were: $\beta$-actin, forward: (5'-CCAGAGCAA GAGAGGCATCC-3') and reverse: (5'-CAACTGTCTCCA TGTCGTCC-3'); MIP-2, forward: (5'-AACATCCAGAGC TTGAGTGTGAC-3') and reverse: (5'-GCCTTGCCTTTG TTCAGTATCTT-3'); TNF- $\alpha$,forward:(5'-CAGCCGATTTGC TATCTCATACC-3') and reverse: (5'-GTACTTGGGCAG ATTGACCTCAG-3'). PCR conditions were: $94^{\circ} \mathrm{C}$ for $2 \mathrm{~min}$, followed by 30 cycles of $94^{\circ} \mathrm{C}$ for $30 \mathrm{sec}, 58^{\circ} \mathrm{C}$ for $30 \mathrm{sec}$ and $72^{\circ} \mathrm{C}$ for $1 \mathrm{~min}$. The final extension was at $72^{\circ} \mathrm{C}$ for $10 \mathrm{~min}$. PCR products were analyzed on $1.2 \%(\mathrm{~W} / \mathrm{V})$ agarose gel containing $0.5 \mathrm{mg} / \mathrm{ml}$ ethidium bromide, visualized under UV light band density, and analyzed and quantified with the software Image $\mathrm{J} 2 \mathrm{x}$.

Statistical analysis. Data are presented as the means \pm standard deviation (SD). The Student's t-test and ANOVA were used to determine significance. Statistical analysis was performed using SPSS 10.0 for windows software. Differences were considered significant at $\mathrm{P}<0.05$.

\section{Results}

Effect of DDP toxicity in vivo. Following the intraperitoneal injection of DDP, reduced activity and food intake with sparse dull hair and weight loss were observed for the mice. The 14 and $15.5 \mathrm{mg} / \mathrm{kg}$ body weight DDP-treated mice were in a poor state: they huddled in a group with retarded activity and began to die on the 2nd day of medication, with no mice surviving after 4 days. However, the $12.5 \mathrm{mg} / \mathrm{kg}$ body weight DDP-treated mice had maximum survival rate and were used in subsequent experiments to observe the effects of G31P with a tolerable high dose of DDP in H22 HCC mice.

G31P and DDP additively inhibit the proliferation of $\mathrm{H} 22$ hepatocarcinoma cells. DDP reduced $\mathrm{H} 22$ viability in a dosedependent manner in vitro. The data also showed that the drug combination scheme had more effective inhibitory effects on $\mathrm{H} 22$ cell viability than DDP alone ( $<<0.05$; Fig. 1).

To compare tumor growth in vivo among the different groups, tumor volume and weight were measured. Control group tumors continued to grow, as compared to those in the G31P and DDP groups. Following treatment with DDP, tumors in the DDP group did not grow for a short period, but started growing after 7 days, whereas, tumors in the DDP+G31P group grew extremely slowly during drug treatment. Tumor mass in the DDP+G31P group was significantly lower than that in the DDP and G31P groups $(\mathrm{P}<0.05$; Fig. 1) and the control group with significant differences $(\mathrm{P}<0.01$; Fig. 1). The inhibition rate of the DDP, G31P and DDP+G31P groups was $38.40,40.74$ and $74.80 \%$, respectively, and the general state of mice in the DDP+G31P group was significantly improved as compared to the DDP group and relatively agile activity was observed.

Histopathological examination of tumor tissues. Primary tumors were sectioned and stained with $\mathrm{H} \& \mathrm{E}$. H22 cells of different shape and size were patchy or diffused in tumor tissue with large, hyperchromatic nucleus. A large proportion of the nucleus but less cytoplasm was evident in cells. Significant necrosis, cytoplasmic shrinkage and cell fragmentation were not identified in the control group as compare to the remaining three groups. The DDP+G31P group showed a significant tumor necrotic area and cell debris with large amounts of nuclear fragmentation as compared to the DDP and G31P groups (Fig. 2).

G31P reduces the expression of EGFR, VEGF, MMP-2 and $N F-\kappa B$ in tumor tissue. Western blot analysis was performed to evaluate EGFR, MMP-2 and VEGF-A expression in tumor tissue of the control, DDP, G31P and DDP+G31P groups (Fig. 3). We found that EGFR, MMP-2 and VEGF-A levels in the $\mathrm{DDP}+\mathrm{G} 31 \mathrm{P}$ group were significantly lower than those of the control group ( $\mathrm{P}<0.01$ vs. control). The difference of EGFR and MMP-2 between the DDP+G31P and alone drug treatment groups (DDP and G31P) was significant $(\mathrm{P}<0.05$ vs. $\mathrm{DDP}+\mathrm{G} 31 \mathrm{P})$. The G31P treatment group markedly inhibited the expression of EGFR and VEGF-A ( $\mathrm{P}<0.05$ vs. control). Significant VEGF-A inhibition was also identified in the DDP treatment group ( $\mathrm{P}<0.05$ vs. control).

Immunohistochemical analysis was performed to evaluate EGFR, VEGF-A and NF- $\kappa$ B expression in the control, DDP, G31P and DDP+G31P groups (Fig. 2). The evident difference of EGFR, VEGF-A and NF- $\kappa \mathrm{B}$ was detected between the $\mathrm{DDP}+\mathrm{G} 31 \mathrm{P}$ and control groups. A major difference in $\mathrm{NF}-\kappa \mathrm{B}$ 
A

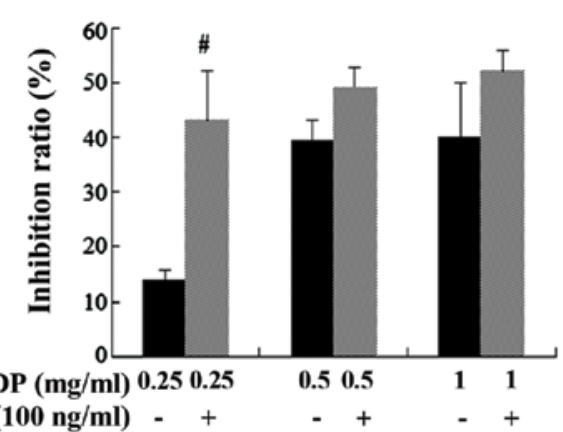

C

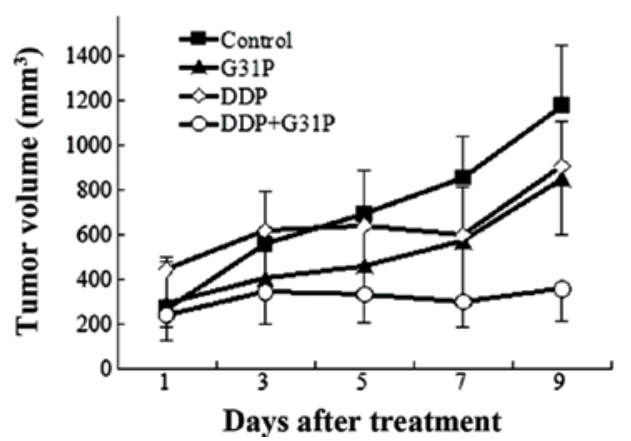

B
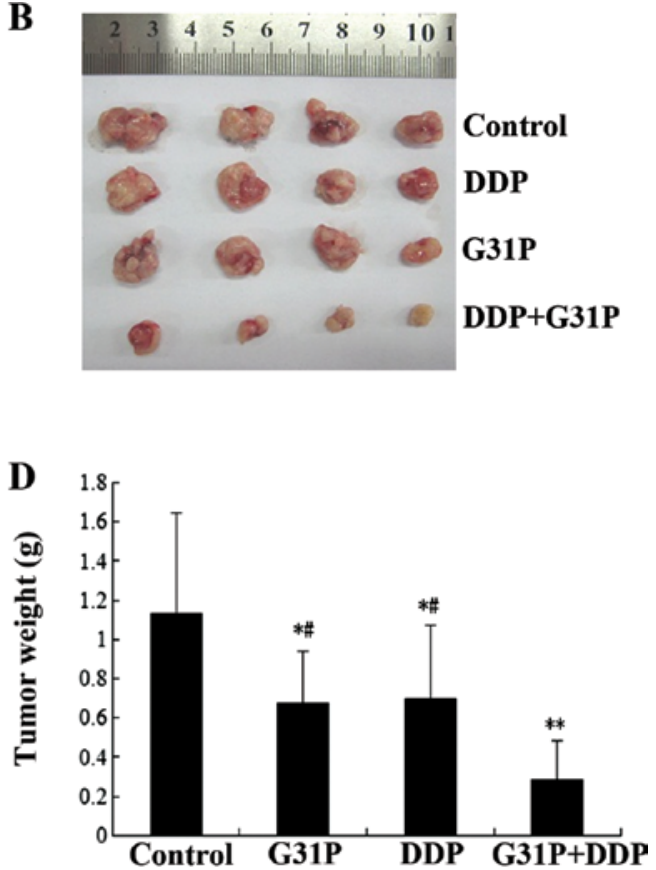

Figure 1. Effect of the combined treatment of DDP and G31P on the inhibition of $\mathrm{H} 22$ cell viability. $\mathrm{H} 22$ cells were treated with different dose of DDP $(0.25$, 0.5 and $1 \mu \mathrm{g} / \mathrm{ml})$ and a combination of DDP and G31P $(100 \mathrm{ng} / \mathrm{ml})$ for $24 \mathrm{~h}$. (A) The graph shows the means \pm SD values (n=5) in duplicate. ${ }^{~} \mathrm{P}<0.05 \mathrm{vs}$. DDP. (B) Images of tumor xenografts stripped from each group mice on the 16th day after cell inoculation. (C) Comparison of tumor volume among the groups during drug treatment. (D) Comparison of tumor weight among the groups on 16th day after tumor inoculation. Graphs present values in means \pm SD of tumors where $\mathrm{n}=10$ in each group. ${ }^{*} \mathrm{P}<0.05,{ }^{* *} \mathrm{P}<0.01$ vs. control; ${ }^{*} \mathrm{P}<0.05$ vs. DDP+G31P. DDP, cisplatin.
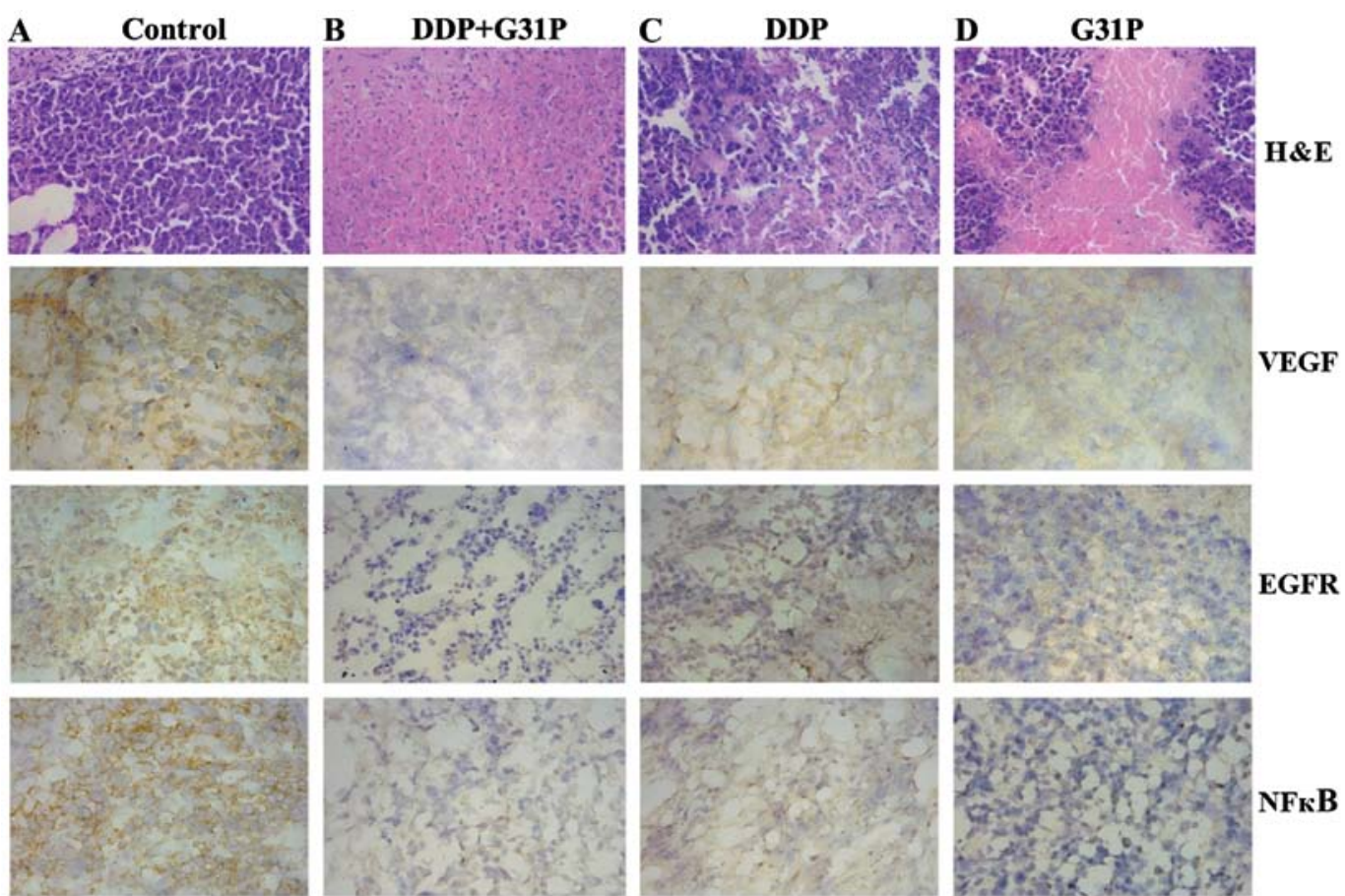

Figure 2. H\&E staining and immunohistochemical analysis of EGFR, VEGF-A and NF- $\kappa B$ expression in tumor tissue. (A) Control group; (B) DDP+G31P group and (C) DDP group; (D) G31P group on the 16th day of tumor development (magnification, $\mathrm{x} 400$ ). H\&E, hematoxylin and eosin; DDP, cisplatin.

expression between the G31P or DDP and control group was found.

G31P improves renal function and reduces kidney tissue damage in cisplatin-induced ARF in mice. Renal function was assessed on the 9th day after drug treatment. As shown in Fig. 4, high-dose cisplatin injection significantly increased BUN and SCr levels $(\mathrm{P}<0.01$ vs. control). By contrast, combined therapy of G31P+DDP significantly reduced BUN and $\mathrm{SCr}(\mathrm{P}<0.01$ vs. DDP) while the G31P group did not show 

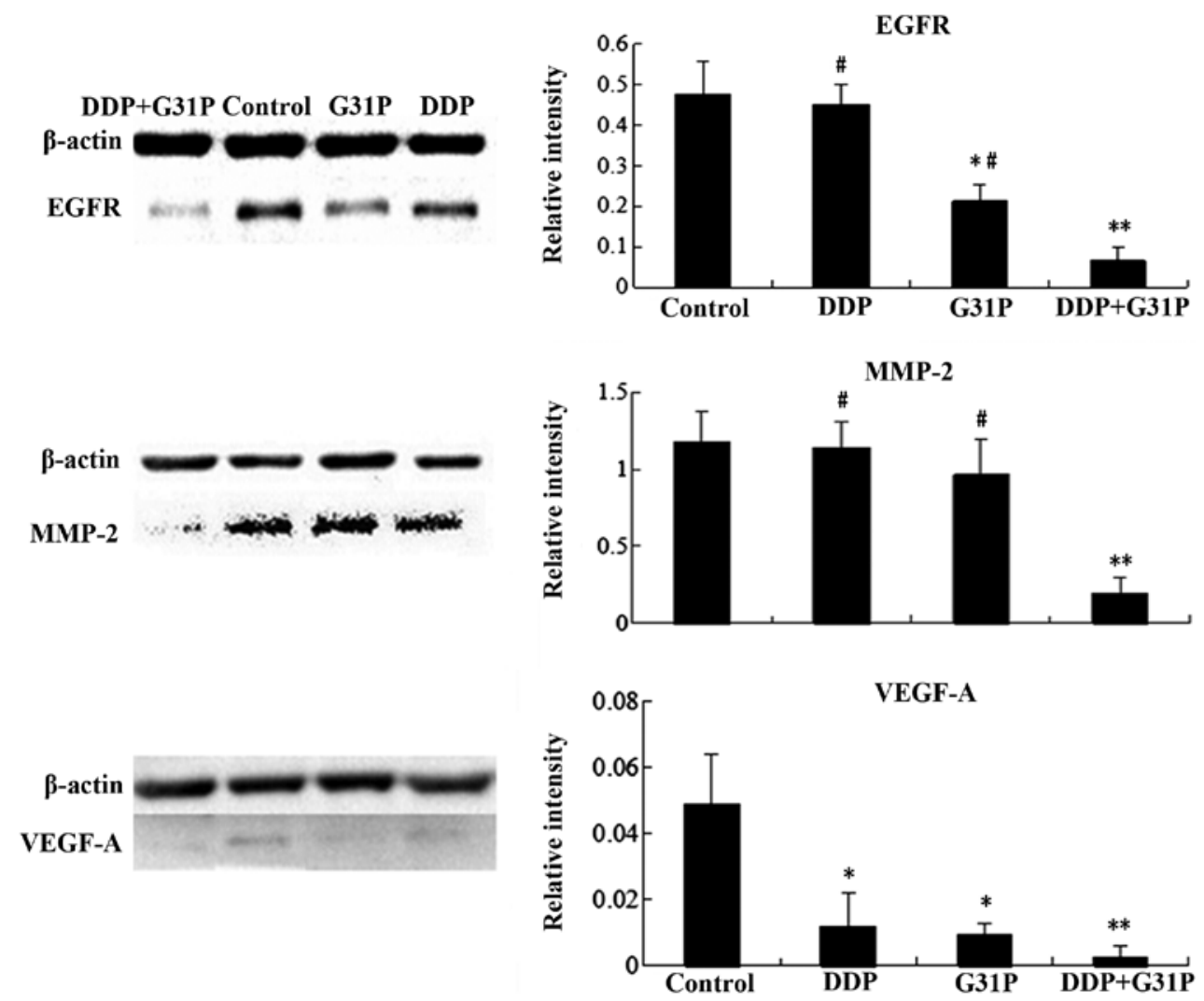

Figure 3. Western blot analysis of EGFR, MMP-2 and VEGF-A expression in tumor tissue. The relative intensity of the western blot bands are shown by semi-quantified analysis with the software Image J2x. ${ }^{*} \mathrm{P}<0.05,{ }^{* *} \mathrm{P}<0.01$ vs. control; ${ }^{\# P} \mathrm{P}<0.05$ vs. DDP+G31P. DDP, cisplatin.
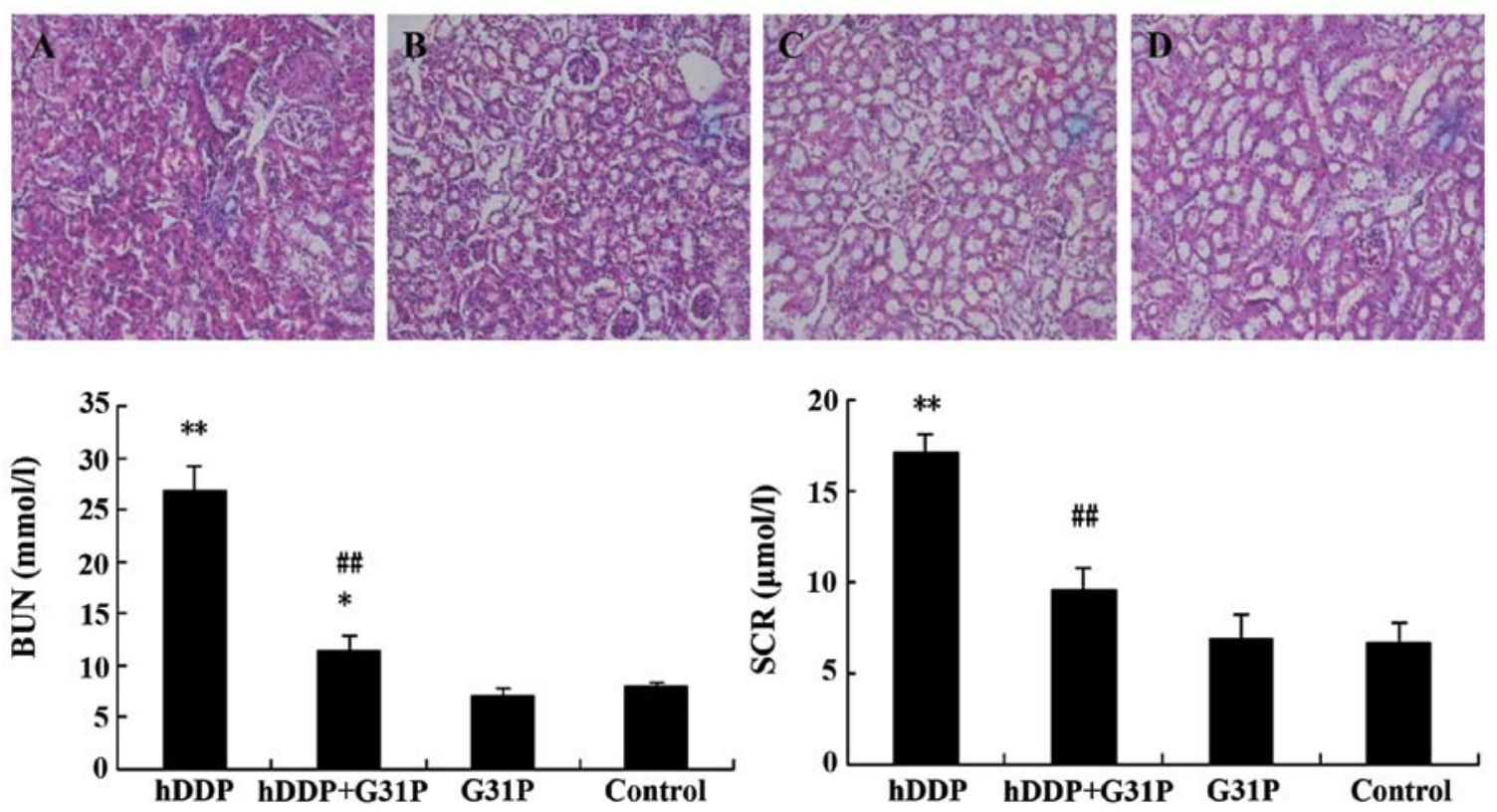

Figure 4. H\&E staining of kidney tissue of (A) DDP, (B) DDP+G31P, (C) G31P and (D) control group on the 9th day after drug treatment (magnification, x200) and comparison of blood urea nitrogen (BUN) and serum creatinine ( $\mathrm{SCr}$ ) for high dose of DDP with or without $\mathrm{G} 31 \mathrm{P}$. ${ }^{* *} \mathrm{P}<0.01 \mathrm{vs}$. control; ${ }^{*} \mathrm{P}<0.05 \mathrm{vs}$. control; ${ }^{\# \#} \mathrm{P}<0.01$ vs. DDP. H\&E, hematoxylin and eosin; DDP, cisplatin.

any significant change of BUN and $\mathrm{SCr}$ compared with the control group. Tissues were resected from the kidney for histopathological examination using H\&E staining from mice of the DDP, DDP+G31P, G31P and control groups (Fig. 4). In the DDP group, cisplatin caused renal damage with loss of the brush border, and necrosis of tubular cells. Tubular structure was disorganized, and fibrous connective tissue hyperplasia was evident. The tubular injury score of the DDP group was $4.0 \pm 0.36$. In the G31P+DDP group, we found that G31P treatment significantly reduced these changes with improvement of 

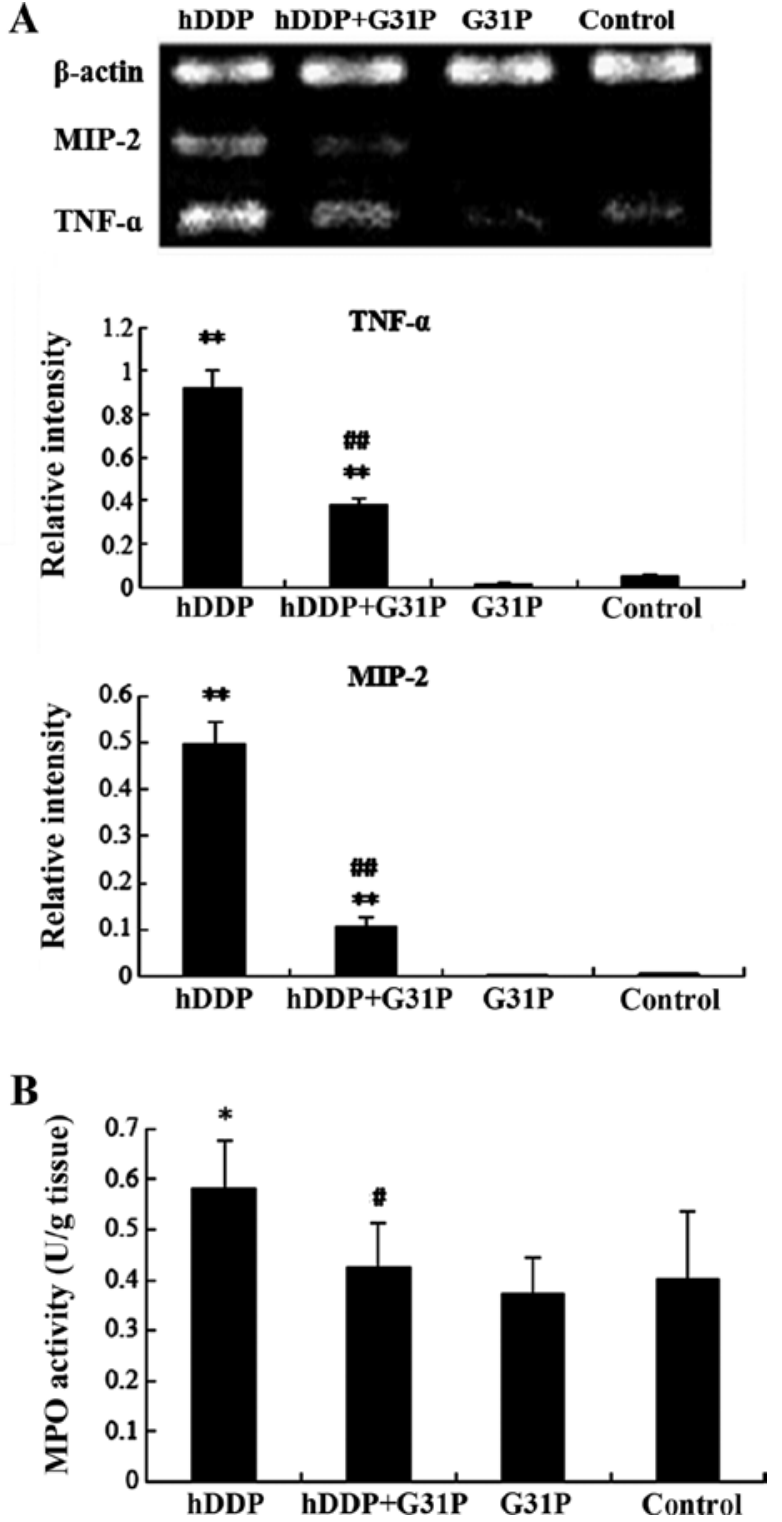

Figure 5. G31P reduces inflammatory cytokines and MPO activity in kidney tissue. (A) Detection of TNF- $\alpha$ and MIP-2 in kidney tissue by RT-PCR. The relative intensity of the bands is shown by semi-quantified analysis with the software Image J2x. ${ }^{* *} \mathrm{P}<0.01$ vs. control; ${ }^{\# \#} \mathrm{P}<0.01$ vs. DDP. (B) MPO activity of kidney tissue for the DDP, DDP+G31P, G31P and control groups. " $\mathrm{P}<0.05$ vs. control; ${ }^{\mathrm{P}} \mathrm{P}<0.05$ vs. DDP. MPO, myeloperoxidase; DDP, cisplatin.

the tubular injury score $(1.0 \pm 0.20)$ while the G31P and control groups did not show significant tubular structure destruction, with scores of $0.3 \pm 0.47$.

G31P reduces inflammatory cytokines and MPO activity in kidney tissue. TNF- $\alpha$ and MIP-2 levels in kidney of the DDP group were significantly higher than those of the control group $(\mathrm{P}<0.01)$. However, G31P treatment significantly reduced the levels of TNF- $\alpha$ and MIP-2 in kidney. There was an obvious difference in the mRNA expression of TNF- $\alpha$ and MIP-2 between the DDP and DDP+G31P groups ( $\mathrm{P}<0.01$, Fig. 5).

To determine the neutrophil infiltration in kidney tissue when treated with a high dose of DDP, MPO activity was measured (Fig. 5). MPO activity of the DDP group was $0.58 \pm 0.10 \mathrm{U} / \mathrm{gm}$ of tissue, which was significantly higher than that of the control group at $0.40 \pm 0.13 \mathrm{U} / \mathrm{gm}$ of tissue $(\mathrm{P}<0.05)$.
MPO activity of the DDP+G31P group was $0.42 \pm 0.09 \mathrm{U} / \mathrm{gm}$ of tissue, which was significantly lower than that of the DDP group $(\mathrm{P}<0.05)$. However, MPO showed no significant difference between the G31P group ( $0.37 \pm 0.07 \mathrm{U} / \mathrm{gm}$ of tissue) and the control group $(0.40 \pm 0.13 \mathrm{U} / \mathrm{gm}$ of tissue).

\section{Discussion}

Results from the present study have shown that combined therapy of G31P and DDP increased tumor deterioration and reduced high-dose DDP-induced nephrotoxicity in H22 HCC-bearing mice by inhibiting renal tubular endothelial cell necrosis and blocking inflammatory cell infiltration. Similar results were considered as G31P highly effective in blocking neutrophil recruitment into the microbial and nonmicrobial inflammatory response (17).

DDP is a chemotherapeutic drug used clinically for the treatment of many types of tumors including HCCs. DDP induces apoptosis in tumor cells by affecting the metabolism of proteins and damages the structure of the cell membrane (18). The antitumor effect of DDP is dose-dependent and as it is mainly excreted by kidneys, causes substantial dose-dependent toxic renal side effects. Nephrotoxicity is frequent and is the major limitation in cisplatin-based chemotherapy $(5,6)$. There are several mechanisms that contribute to renal dysfunction following exposure to DDP including direct tubular toxicity in the form of necrosis of endothelial cells cause the excretion of cytokines, with neutrophil infiltration leading to inflammation $(19,20)$. Due to limited effectiveness when any anti-carcinogen is used alone and an obviously increased toxicity with dose increase, there is no exception of combined therapy. Furthermore, combined chemotherapy contributes to improving therapeutic effectiveness, dispersing toxicity and overcoming drug resistance (21).

IL-8 is considered one of the major mediators of the inflammatory response and this cancer-derived chemokine contributes to tumor progression through the chemoattractive function and regulation of angiogenesis, cancer cell growth and survival, as well as tumor cell migration (22). Expression of IL-8 was detected in human malignant liver tumor tissue $(23,24)$ where endothelial cells are present and are responsible for lymphocyte recruitment particularly in neutrophils through the activation of CXCR1/2 (25). Consequently, by antagonizing IL-8 by blocking its interaction with CXCR1/2, G31P inhibits the biological activity of IL-8, thereby inhibiting the proliferation of $\mathrm{H} 22$ carcinoma, as mentioned above, with decreased MTT activity. Furthermore, G31P deteriorates the development of cancer in vivo by inhibiting the implanted hepatocarcinoma in mice and prolongs the survival phase of mice with no obvious toxicity. These result are in concordance with previously reported findings demonstrating G31P tumor growth inhibition and apoptosis in prostate and lung cancers (15).

HCCs are vascular tumors and increased levels of VEGF, MMP-2 and NFאB expression has been associated with increased microvessel density (MVD) and tumor growth $(26,27)$. G31P suppression of the angiogenic effect of ELR-CXC chemokines was also proven in prostate cancer (15). IL-8 increased tumor proliferation through the transactivation of EGFR (28). Our results showed that G31P treatment 
reduced EGFR expression, which downstream leads to tumor growth inhibition and cause apoptosis.

TNF- $\alpha$ is crucial in the pathogenesis of cisplatin-induced ARF (29). Our results confirm that high-dose DDP therapy increased proinflamatory cytokines including TNF- $\alpha$ and MIP-2. MPO is an enzyme mainly released by activated neutrophils and characterized by efficient pro-oxidative and proinflammatory properties in mouse kidney (30). Treatment with G31P reduced TNF- $\alpha$ and MIP-2 expression and MPO activity was evidently decreased, confirming that G31P significantly reduced neutrophil chemotaxis to the site of the infection and effectively alleviated the inflammatory response and reduced unnecessary tissue damage to improve the survival rate.

In conclusion, combined G31P and DDP significantly inhibited the growth of mouse hepatoma cells and the expression of EGFR, VEGF, MMP-2 and NF- $\kappa$ B of tumor tissues. G31P enhances the efficacy of DDP in cancer treatment, mitigates cisplatin-induced nephrotoxicity and improves the survival rate of mice by reducing renal pathological damage, infiltration of neutrophils in kidney, and the expression of TNF- $\alpha$ and MIP-2 in kidney tissues, caused by DDP. These findings may provide a new approach for the prevention and treatment of cancer.

\section{Acknowledgements}

This study was supported by a grant from the National Science Foundation of China (grant no. NSFC30772023).

\section{References}

1. Forner A, Llovet JM and Bruix J: Hepatocellular carcinoma. Lancet 379: 1245-1255, 2012.

2. Shen FZ, Wang J, Liang J, Mu K, Hou JY and Wang YT: Low-dose metronomic chemotherapy with cisplatin: can it suppress angiogenesis in $\mathrm{H} 22$ hepatocarcinoma cells? Int J Exp Pathol 91: 10-16, 2010.

3. Ozdogan O, Ertay T, Arslan G, et al: Does cisplatin chemotherapy decrease the MDP uptake of normal bone? An experimental study. Ann Nucl Med 22: 357-362, 2008.

4. Arany I and Safirstein RL: Cisplatin nephrotoxicity. Semin Nephrol 23: 460-464, 2003.

5. Bonventre JV: Pathophysiology of ischemic acute renal failure. Inflammation, lung-kidney cross-talk, and biomarkers. Contrib Nephrol 144: 19-30, 2004.

6. Ramesh G and Reeves WB: TNFR2-mediated apoptosis and necrosis in cisplatin-induced acute renal failure. Am J Physiol Renal Physiol 285: 610-618, 2003.

7. Faubel S, Lewis EC, Reznikov L, Ljubanovic D, Hoke TS, Somerset H, Oh DJ, Lu L, Klein CL, Dinarello CA and Edelstein CL: Cisplatin-induced acute renal failure is associated with an increase in the cytokines interleukin (IL)-1 $\beta$, IL-18, IL-6, and neutrophil infiltration in the kidney. J Pharmacol and Exp Ther 322: 8-15, 2007.

8. Mukaida N: Pathophysiological roles of interleukin-8/CXCL8 in pulmonary diseases. Am J Physiol Lung Cell Mol Physiol 284: L566-L577, 2003.

9. Wang Y, Wang W, Wang L, Wang X and Xia J: Regulatory mechanisms of interleukin- 8 production induced by tumor necrosis factor- $\alpha$ in human hepatocellular carcinoma cells. J Cell Mol Med 16: 496-506, 2012.

10. Zhao X, Li F, Town JR, Zhang X, Wang W and Gordon JR: Humanized forms of the CXCR1/CXCR2 antagonist, bovine CXCL8 $8_{(3-74)} \mathrm{K} 11 \mathrm{R} / \mathrm{G} 31 \mathrm{P}$, effectively block ELR-CXC chemokine activity and airway endotoxemia pathology. Int Immunopharmacol 7: 1723-1731, 2007.
11. Zhao X, Town JR, Li F, Zhang X, Cockcroft DW and Gordon JR: ELR-CXC chemokine receptor antagonism targets inflammatory responses at multiple levels. J Immunol 182: 3213-3222, 2009.

12. Gordon JR, Li F, Zhang X, Wang W, Zhao X and Nayyar A: The combined CXCR1/CXCR2 antagonist CXCL8 $8_{(3-74)} \mathrm{K} 11 \mathrm{R} / \mathrm{G} 31 \mathrm{P}$ blocks neutrophil infiltration, pyrexia, and pulmonary vascular pathology in endotoxemic animals. J Leukoc Biol 78: 1265-1272, 2005.

13. Zhao X, Town JR, Li F, Li W, Zhang X and Gordon JR: Blockade of neutrophil responses in aspiration pneumonia via ELR-CXC chemokine antagonism does not predispose to airway bacterial outgrowth. Pulm Pharmacol Ther 23: 22-28, 2010.

14. Zhao X, Town JR, Yang A, Zhang X, Paur N, Sawicki G and Gordon JR: A novel ELR-CXC chemokine antagonist reduces intestinal ischemia reperfusion-induced mortality, and local and remote organ injury. J Surg Res 162: 264-273, 2010.

15. Liu X, Peng J, Sun W, Yang S, Deng G, Li F, Cheng JW and Gordon JR: G31P, an antagonist against CXC chemokine receptors 1 and 2, inhibits growth of human prostate cancer cells in nude mice. Tohoku J Exp Med 228: 147-156, 2012.

16. Qin Y, Fan F, Zhao Y, Cui Y, Wei X, Kohama K, Gordon JR, Li F and Gao Y: Recombinant human CXCL8 (3-72) K11R/G31P regulates smooth muscle cell proliferation and migration through blockage of interleukin-8 receptor. IUBMB Life 65: 67-75, 2013.

17. Wei J, Peng J, Wang B, Qu H, Wang S, Faisal A, Cheng JW, Gordon JR and Li F: CXCR1/CXCR2 antagonism is effective in pulmonary defense against Klebsiella pneumoniae infection. Biomed Res Int 2013: 720975, 2013.

18. Shen DW, Pouliot LM, Hall MD and Gottesman MM: Cisplatin resistance: a cellular self-defense mechanism resulting from multiple epigenetic and genetic changes. Pharmacol Rev 64: 706-721, 2012.

19. Friedewald JJ and Rabb H: Inflammatory cells in ischemic acute renal failure. Kidney Int 66: 486-491, 2004.

20. Okusa MD: The inflammatory cascade in acute ischemic renal failure. Nephron 90: 133-138, 2002.

21. Wang W, Qin SK, Chen BA and Chen HY: Experimental study on antitumor effect of arsenic trioxide in combination with cisplatin or doxorubicin on hepatocellular carcinoma. World $\mathbf{J}$ Gastroenterol 7: 702-705, 2001.

22. Yuan A, Chen JJ, Yao PL and Yang PC: The role of interleukin-8 in cancer cells and microenvironment interaction. Front Biosci 10: 853-865, 2005

23. Xie K: Interleukin-8 and human cancer biology. Cytokine Growth Factor Rev 12: 375-391, 2001

24. Harimoto N, Shirabe K, Abe T, et al: Interleukin-8 producing hepatocellular carcinoma with pyrexia. HPB Surg 1: 461-492, 2009.

25. Yoong KF, Afford SC, Jones R, Aujla P, Qin S, Price K, Hubscher SG and Adams DH: Expression and function of CXC and $\mathrm{CC}$ chemokines in human malignant liver tumors: a role for human monokine induced by gamma-interferon in lymphocyte recruitment to hepatocellular carcinoma. Hepatology 30: 100-111, 1999.

26. Yang ZF and Poon RT: Vascular changes in hepatocellular carcinoma. Anat Rec 291: 721-734, 2008

27. Tanaka H, Yamamoto M, Hashimoto N, Miyakoshi M, Tamakawa S, Yoshie M, Okusashi Y, Yokoyama K, Yaginuma Y and Ogawa K: Hypoxia-independent overexpression of hypoxia-inducible factor $1 \alpha$ as an early change in mouse hepatocarcinogenesis. Cancer Res 66: 11263-11270, 2006.

28. Luppi F, Longo AM, de Boer WI, Rabe KF and Hiemstra PS: Interleukin-8 stimulates cell proliferation in non-small cell lung cancer through epidermal growth factor receptor transactivation. Lung Cancer 56: 25-33, 2007.

29. Wu Y and Zhou BP: TNF- $\alpha / \mathrm{NF}-\kappa \mathrm{B} /$ Snail pathway in cancer cell migration and invasion. Br J Cancer 102: 639-644, 2010.

30. Guilpain P, Servettaz A, Batteux F, Guillevin L and Mouthon L: Natural and disease associated anti-myeloperoxidase (MPO) autoantibodies. Autoimmun Rev 7: 421-425, 2008. 